\title{
Risk factors and outcomes of uterine rupture in Singapore: Emerging trends
}

Shu Qi Tan, ${ }^{1}{ }_{M B B S},{ }_{M R C O G}$, Li Houng $\underline{\text { Chen }},{ }^{2} M B B S$, Dhilshad Bte Muhd Abdul Qadir, ${ }^{1} M B B S, M R C S$, Bernard SM $\underline{\text { Chern, }}{ }^{1}$ MBBS, FRCOG (UK), MRANZCOG, George SH Yeo, ${ }^{1}$ MBBS, FRCOG, FAMS

\begin{abstract}
Introduction: Uterine rupture is uncommon but has catastrophic implications on the pregnancy. A scarred uterus and abnormal placentation are known contributory factors. The aim of our study was to review the contributing factors, clinical presentation, complications and management of uterine rupture in our population in light of the changing nature of modern obstetric practices.

Methods: A retrospective observational study was conducted at KK Women's and Children's Hospital by studying proven cases of uterine rupture in the period between January 2003 and December 2014. These cases were analysed according to their past history, clinical presentation, complications, management and outcome.

Results: A total of 48 cases of proven uterine rupture were identified. The incidence of uterine rupture was 1 in 3,062 deliveries. The ratio of scarred uterus rupture to unscarred uterus rupture was approximately 3:1. The most common factor was previous lower segment caesarean section for the scarred group, followed by a history of laparoscopic myomectomy. Abdominal pain was the common clinical presentation in the antenatal period, while abnormal cardiotocography findings were the most common presentation in intrapartum rupture.

Conclusion: There is a notable shift in the trend of uterine rupture cases given the increasing use of laparoscopic myomectomy and elective caesarean sections. While ruptures from these cases were few, their presentation in the antenatal period calls for diligent monitoring with informed patient involvement in their pregnancy care.
\end{abstract}

Ann Acad Med Singap 2021;50:5-15

Keywords: Antenatal, laparoscopic myomectomy, birth after caesarean, rupture, VBAC

\section{INTRODUCTION}

Uterine rupture is a catastrophic life-threatening complication of pregnancy with associated high maternal and neonatal morbidity and mortality. The incidence of uterine rupture varies with geographical location and obstetric practice. With the changes in obstetric practice over the years, caesarean section rates have increased in our population with undesirable consequences. The increasing numbers of caesarean sections for maternal requests, the decline of vaginal breech deliveries, and the increasing use of laparoscopic surgeries, especially laparoscopic myomectomies are contributory factors. The consequence of uterine rupture can be catastrophic. It is important to review the contributing factors, clinical presentation, complications and management of uterine rupture.

\section{METHODS}

A retrospective observational study of uterine rupture case records from January 2003 to December 2014 was performed at the KK Women's and Children's Hospital, the largest maternity hospital in Singapore. The operating theatre record books of the desired period were reviewed to trace the uterine rupture cases. The list of patients with the International Classification of Disease coding for uterine ruptures was also generated from our information system department, and the 2 lists were compiled. Obstetric records of these cases were traced from the Medical Records Office. Only cases of proven uterine rupture were included in the study. Cases of suspected or impending rupture and dehiscence were excluded. This study was reviewed and granted ethical approval by the SingHealth Centralised Institutional Review Board prior to its commencement.

\footnotetext{
${ }^{1}$ Division of Obstetrics and Gynaecology, KK Women's and Children's Hospital, Singapore

${ }^{2}$ Yong Loo Lin School of Medicine, National University of Singapore, Singapore

Correspondence: Dr Shu Qi Tan, Division of Obstetrics and Gynaecology, KK Women's and Children's Hospital, 100 Bukit Timah Road, Singapore 229899.

Email: tan.shu.qi@singhealth.com.sg
} 


\section{RESULTS}

During this 12-year period, there were 147,003 deliveries and 48 cases of uterine rupture at our centre. The overall incidence of uterine rupture was 1 in 3,062 deliveries. The overall ratio of scarred to unscarred uteri was approximately $3: 1$.

The majority of cases occurred in women less than 35 years old $(72.9 \%)$ and $79.2 \%$ of these mothers were multiparous. There was 1 case of twin pregnancy in our case series in the scarred group. All other pregnancies were singleton pregnancies.

The most common reason for a scarred uterus was 1 previous caesarean section $(65.8 \%)$. Laparoscopic myomectomy and 2 previous caesarean sections were the next most common reasons for a scarred uterus at $13.2 \%$ each, followed by 3 previous caesarean sections $(5.3 \%)$ and previous uterine rupture $(2.6 \%)$. There was 1 case of recurrence of uterine rupture in the scarred uteri group from previous right cornual interstitial pregnancy at 18 weeks.

The mean duration from the previous pregnancy was 3.3 years. Only 1 patient had a short interpregnancy interval of less than a year. All patients with previous laparoscopic myomectomies and previous uterine rupture had an interval of more than 12 months between the operation and uterine rupture episode.

The majority of the uterine ruptures occurred during the third trimester $(83.3 \%)$. However, a larger proportion of the unscarred uteri group experienced the rupture during the second trimester $(33.3 \%)$ compared to the scarred uteri group (11.1\%). There were no cases of uterine rupture in the first trimester. This could be due to the classification of cases as part of this retrospective study. Ruptures in the first trimester may have been classified as ruptured ectopic pregnancies.

Uterine rupture occurred most frequently during the intrapartum period $(62.5 \%)$. For women with 1 previous caesarean section, $84 \%$ presented in the intrapartum period. Among these cases with 1 previous caesarean that ruptured in the intrapartum period, 3 cases used prostaglandin in labour, and 2 cases used oxytocin.

In contrast, women with scarred uteri of other aetiologies (including 2 or more previous caesarean sections, and previous uterine rupture) presented mainly with scar rupture in the antenatal period. Of note, all 5 patients with a previous laparoscopic myomectomy had the scar rupture antenatally. Two of these patients' scars ruptured in the second trimester, and the remaining 3 ruptured in the third trimester. The details of uterine rupture in relation to labour are summarised in Table 1.

The mean duration of labour with intrapartum uterine ruptures was 9.2 hours. Six cases (21.4\%) of intrapartum ruptures had prolonged active labour of 12 hours or more.

\section{Maternal presentation}

Abdominal pain was the most common presenting complaint for women with antenatal uterine rupture. For women in labour, the most common presentation was

Table 1. Number of patients with uterine rupture from scarred and unscarred uterus with or without use of prostaglandins and/or oxytocin

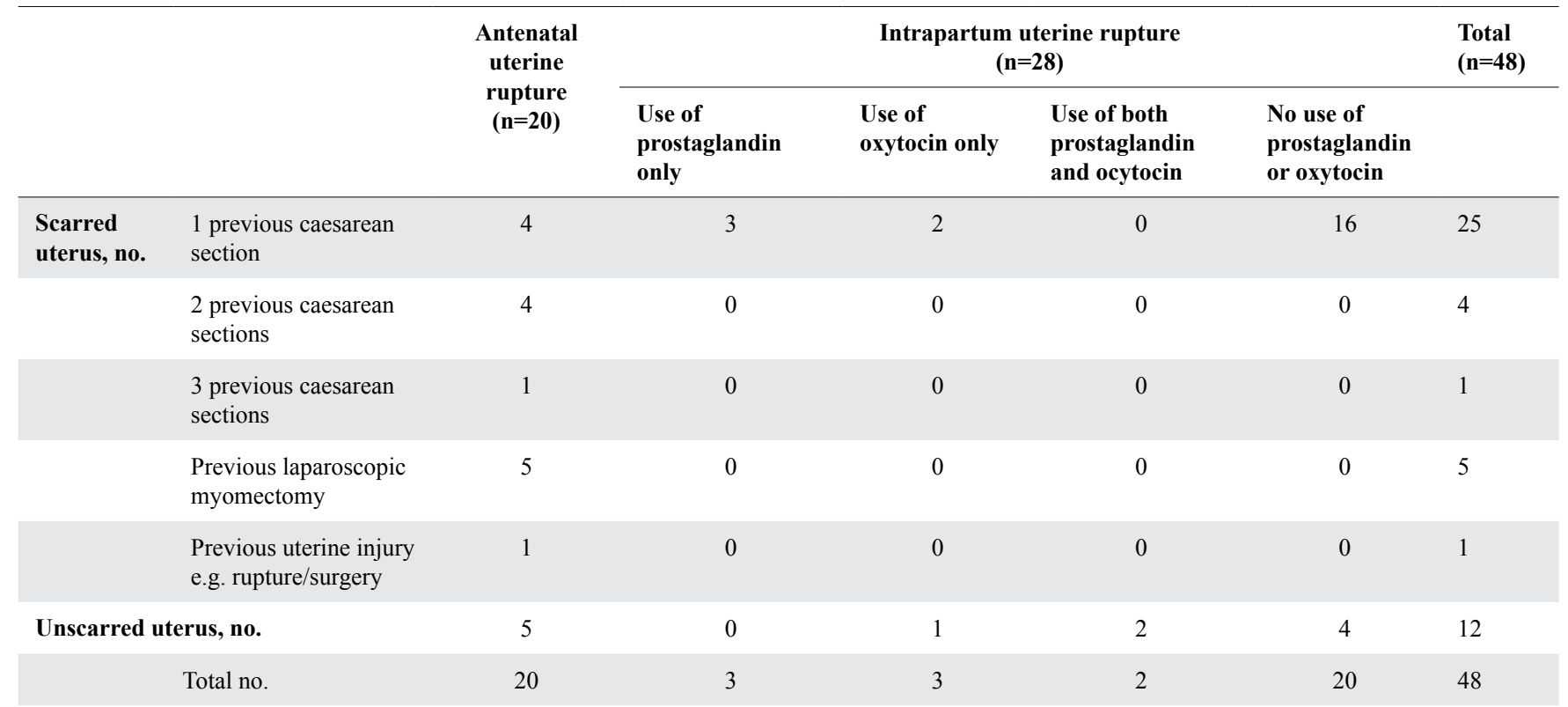


an abnormal cardiotocogram (89.3\%). Multiple presentations may be present simultaneously for each case. The different maternal presentations are summarised in Table 2.

\section{Operative procedures}

Caesarean section with uterine repair sufficed for $89.6 \%$ of the uterine rupture cases. However, 5 cases had severe haemorrhage, necessitating a hysterectomy to secure haemostasis. All of these cases were in the scarred uteri group. One of the patients presented with appendicitis at 17 weeks gestation with an incidental finding of haemoperitoneum due to uterine rupture at laparotomy.

\section{Location of rupture}

The most common location of the rupture was the anterior lower uterine segment (54.2\%), followed by the fundus $(22.9 \%)$.

For those with scarred uteri, $88.9 \%$ of the location of rupture corresponded to the previous scar sites. For women with previous caesarean deliveries, $86.7 \%$ of ruptures occurred at the caesarean site. For women with previous laparoscopic myomectomies, all myomectomies were performed at other centres. As no surgical details were available, it was not known if the rupture site corresponded to the site of the previous myomectomy. All cases of women with previous laparoscopic myomectomy had ruptures at the fundus.

The most common location for the unscarred group was the fundus $(41.7 \%)$, followed by the posterior uterine wall (33.3\%).

\section{Maternal mortality and morbidity}

There were no maternal deaths in this series of 48 cases. Haemoperitoneum was noted in half of the cases $(50 \%)$. Notably, the patients with previous laparoscopic myomectomy had more severe maternal bleeding and adverse consequences from the rupture. All cases had significant haemoperitoneum, and one suffered from end organ damage secondary to hypovolaemic shock. More than half of the cases of rupture from a previous caesarean scar had no serious maternal complications (Table 3).

\section{Fetal outcomes}

Of the 48 cases, 12 cases resulted in stillbirth and neonatal death $(25.0 \%)$. Six stillborns belonged to the scarred uteri group. The 4 stillbirths in the unscarred group occurred before 26 weeks gestation. More newborns in the scarred uteri group required stay in the neonatal intensive care unit (NICU) and resuscitation at birth compared to the unscarred uteri group. The average birth weight of life baby at birth in the scarred and unscarred group was 2,760g and 2,803g respectively (Table 4).

Table 2. Maternal presentation of uterine rupture

\begin{tabular}{|c|c|c|c|}
\hline \multicolumn{4}{|c|}{ Antenatal uterine rupture $(\mathrm{n}=\mathbf{2 0})$} \\
\hline Presentation & Scarred uterus $(n=15)$ & Unscarred uterus $(\mathrm{n}=\mathbf{5})$ & Total by each presentation, no. (\%) \\
\hline Abdominal pain & 13 & 4 & $17(85.0)$ \\
\hline Antepartum hemorrhage & 2 & 1 & $3(15.0)$ \\
\hline Reduced fetal movements & 2 & 0 & $2(10.0)$ \\
\hline Maternal shock & 3 & 1 & $4(20.0)$ \\
\hline Bloatedness & 1 & 0 & $1(5.0)$ \\
\hline \multicolumn{4}{|c|}{ Intrapartum uterine rupture $(n=28)$} \\
\hline Presentation & $\begin{array}{l}\text { Scarred uterus, } 1 \text { previous } \\
\text { caesarean section }(\mathrm{n}=21)\end{array}$ & Unscarred uterus $(n=7)$ & Total by each presentation, no. (\%) \\
\hline Abnormal CTG & 19 & 6 & $25(89.3)$ \\
\hline Signs of CPD & 4 & 4 & $8(28.6)$ \\
\hline Loss of station & 1 & 0 & $1(3.6)$ \\
\hline Puerperal pyrexia & 1 & 0 & $1(3.6)$ \\
\hline Scar tenderness & 1 & & $1(3.6)$ \\
\hline Abdominal pain & 1 & 1 & $2(7.1)$ \\
\hline
\end{tabular}

CPD: cephalopelvic disproportion; CTG: cardiotocograph 
Up to half of the antenatal ruptures resulted in stillbirths. There were no stillbirths in the intrapartum group. However, there were 2 subsequent neonatal deaths due to hypoxic ischaemic encephalopathy. NICU admission rates and the need for resuscitation are similar for both groups. Within the scarred group, there was a higher proportion of stillbirths in the laparoscopic myomectomy group $(40.0 \%)$ compared to the caesarean section group (13.3\%). Both stillbirths from the laparoscopic myomectomy group ruptured in the second trimester. All live births from the laparoscopic myomectomy group were admitted to the NICU. Table 5 compares fetal outcomes between antepartum and intrapartum ruptures.

Table 6 gives a summary of all 48 rupture cases to illustrate the type of scar, gestation of rupture, timing of rupture, intrapartum events and neonatal outcomes.

Table 3. Maternal outcomes from scarred and unscarred uterine ruptures (total $n=48$ )

\begin{tabular}{|c|c|c|c|c|c|}
\hline \multirow[t]{2}{*}{ Outcome } & \multicolumn{3}{|c|}{ Scarred $(n=36)$} & \multirow{2}{*}{$\begin{array}{l}\text { Unscarred } \\
(n=12)\end{array}$} & \multirow{2}{*}{$\begin{array}{l}\text { Total by each } \\
\text { outcome, no. }(\%)\end{array}$} \\
\hline & $\begin{array}{l}\text { Previous } \\
\text { caesarean section } \\
(n=30)\end{array}$ & $\begin{array}{l}\text { Laparoscopic } \\
\text { myomectomy } \\
(n=5)\end{array}$ & $\begin{array}{l}\text { Previous } \\
\text { uterine rupture } \\
(n=1)\end{array}$ & & \\
\hline Death & 0 & 0 & 0 & 0 & 0 \\
\hline Significant haemoperitoneum & 11 & 5 & 0 & 8 & $24(50.0)$ \\
\hline Disseminated intravascular coagulation & 1 & 1 & 0 & 1 & $3(6.3)$ \\
\hline Hypovolaemic shock with end organ damage & 0 & 1 & 0 & 0 & $1(2.1)$ \\
\hline Bladder injury & 1 & 0 & 0 & 0 & $1(2.1)$ \\
\hline Uterine atony & 1 & 0 & 0 & 0 & $1(2.1)$ \\
\hline
\end{tabular}

Table 4. Fetal outcomes from scarred and unscarred uterine ruptures (total $n=48$ )

\begin{tabular}{|c|c|c|c|c|c|}
\hline \multirow[t]{2}{*}{ Outcome } & \multicolumn{3}{|c|}{ Scarred $(n=36)$} & \multirow{2}{*}{$\begin{array}{l}\text { Unscarred } \\
(n=12)\end{array}$} & \multirow{2}{*}{$\begin{array}{l}\text { Total by each } \\
\text { outcome, no. }(\%)\end{array}$} \\
\hline & $\begin{array}{l}\text { Previous caesarean } \\
\text { section }(n=30)\end{array}$ & $\begin{array}{l}\text { Previous laparoscopic } \\
\text { myomectomy }(n=5)\end{array}$ & $\begin{array}{l}\text { Previous uterine } \\
\text { rupture }(n=1)\end{array}$ & & \\
\hline Live birth & 26 & 3 & 1 & 8 & $38(75)$ \\
\hline Stillbirth & 4 & 2 & 0 & 4 & $10(20.8)$ \\
\hline Subsequent neonatal death & 2 & 0 & 0 & 0 & $2(4.2)$ \\
\hline NICU stay & 11 & 3 & 1 & 2 & $17(35.4)$ \\
\hline Resuscitation $^{\mathrm{a}}$ & 11 & 3 & 1 & 2 & $17(35.4)$ \\
\hline Apgar score $\leq 6$ at $1 \mathrm{~min}^{\mathrm{b}}$ & 14 & 2 & 0 & 2 & $18(37.5)$ \\
\hline Apgar score $\leq 6$ at $5 \mathrm{~min}$ & 5 & 0 & 0 & 2 & $7(14.6)$ \\
\hline
\end{tabular}

${ }^{a}$ Resuscitative measures include: oxygen, nasal continuous positive airway pressure, positive pressure ventilation, endotracheal tube, chest compressions, epinephrine use

${ }^{\mathrm{b}}$ Apgar 7-10 is excellent, 4-6 is moderately depressed, 0-3 is severely depressed

Table 5. Comparison of fetal outcomes in antenatal and intrapartum uterine ruptures (total $n=48$ )

\begin{tabular}{lll}
\hline Outcome, no. $(\mathbf{\%})$ & Antenatal $(\mathbf{n}=\mathbf{2 0})$ & Intrapartum $(\mathbf{n = 2 8 )}$ \\
\hline Live birth & $10(50.0)$ & $28(100.0)$ \\
Stillbirth & $10(50.0)$ & 0 \\
Subsequent neonatal death & 0 & $2(7.14)$ \\
NICU stay & $8(40.0)$ & $9(32.1)$ \\
Resuscitation & $8(40.0)$ & $9(32.1)$
\end{tabular}




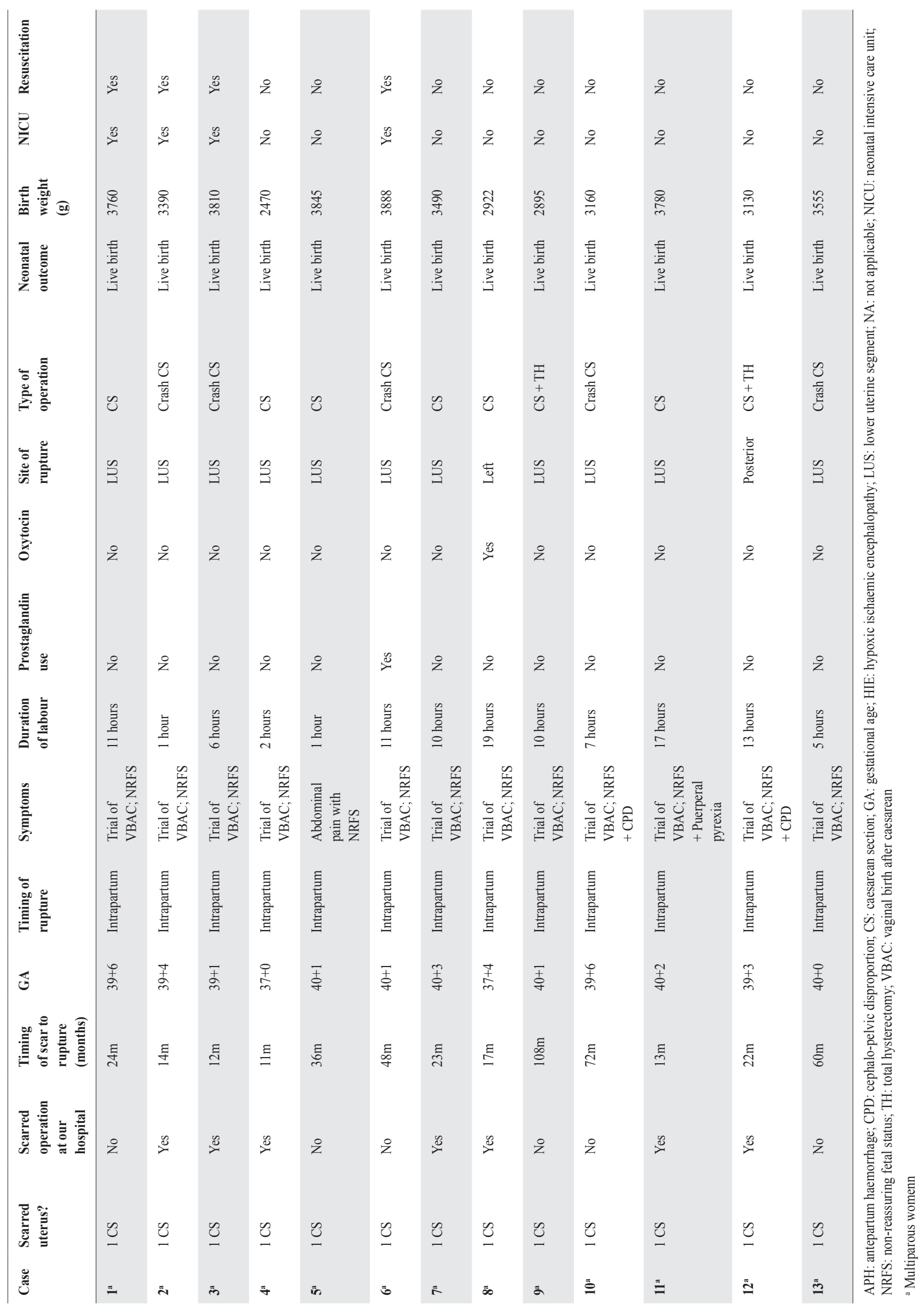




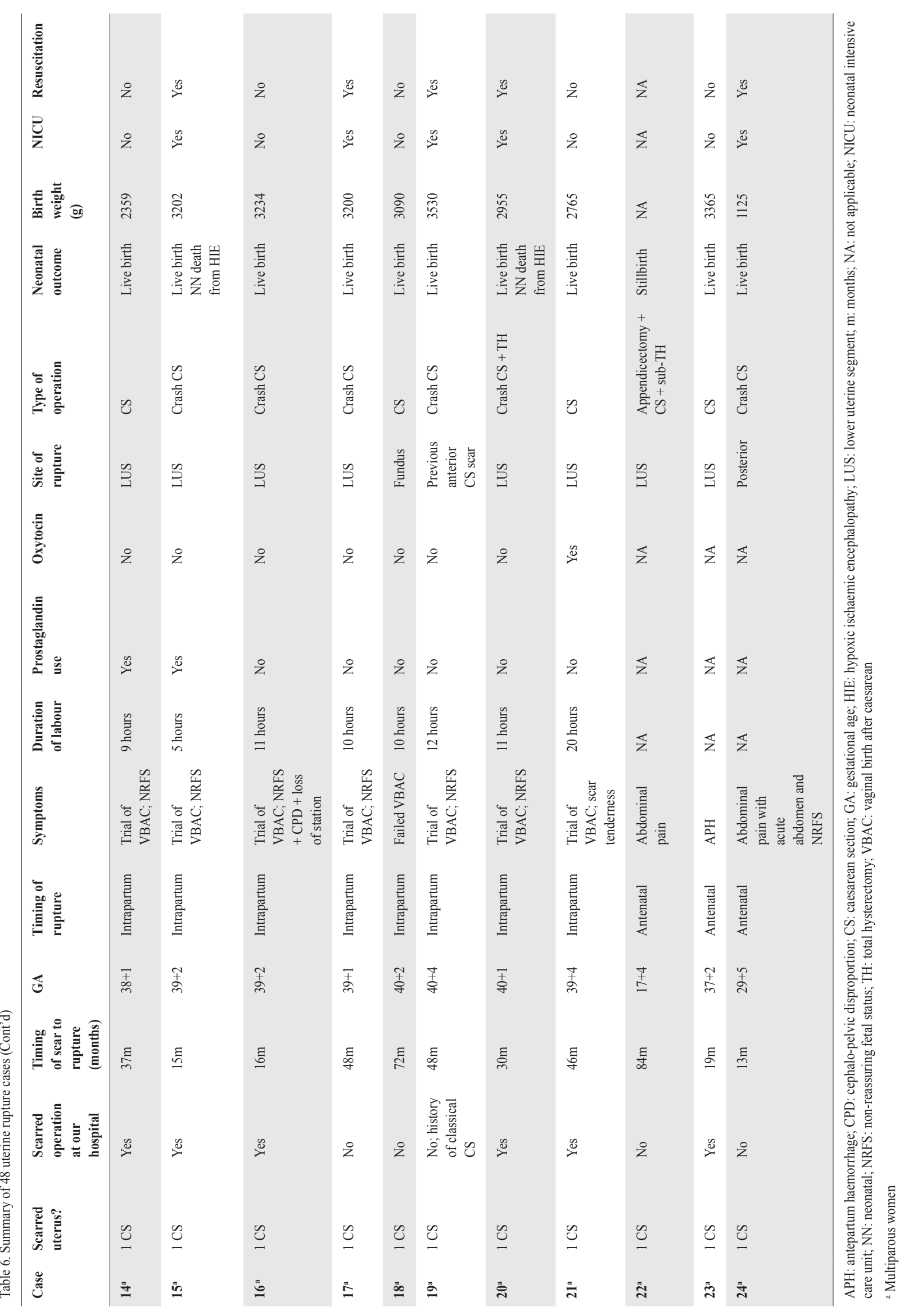




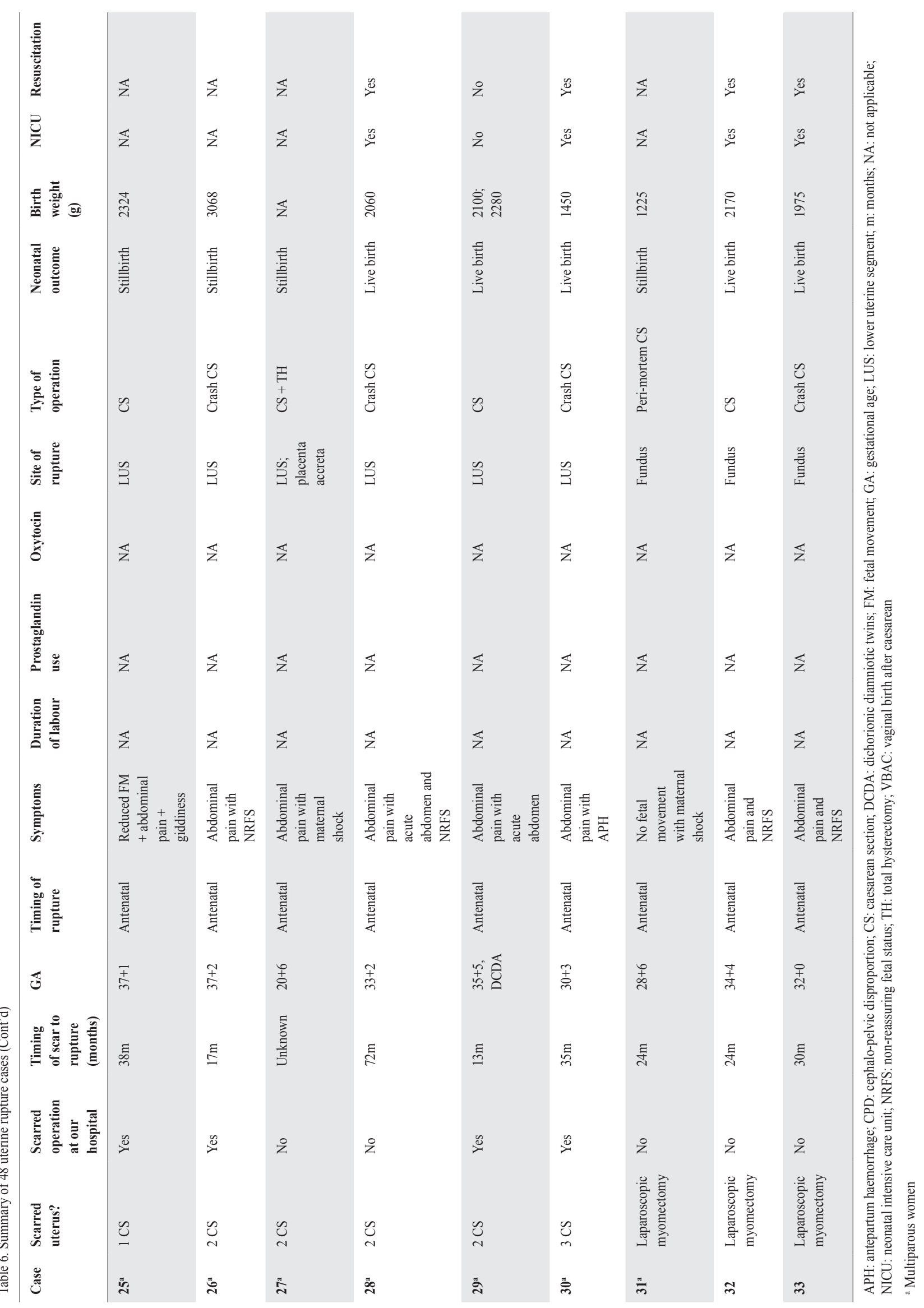




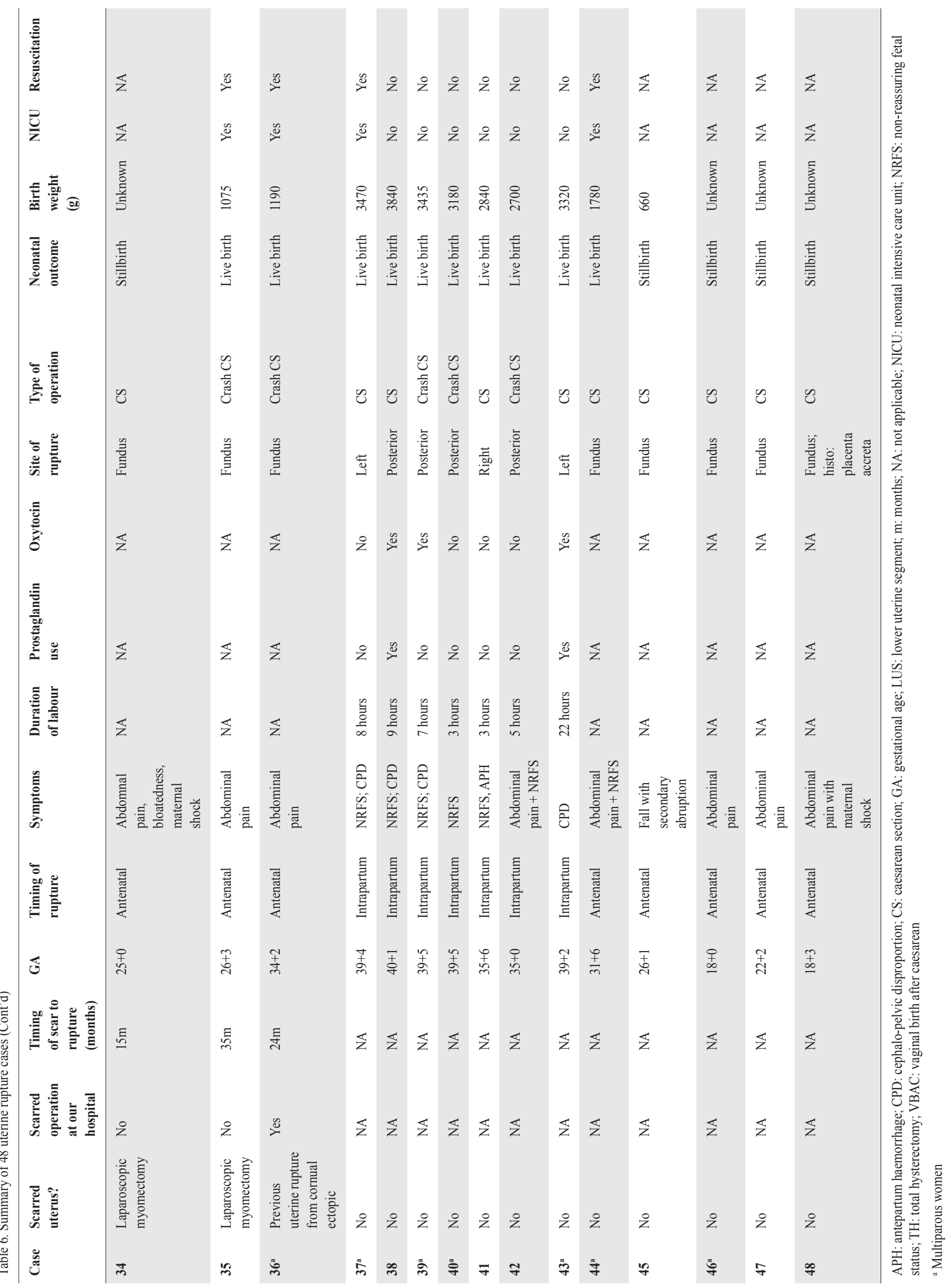




\section{DISCUSSION}

With the shift in obstetric practices towards an increasing trend of caesarean section, the incidence of uterine rupture in our case series has grown in this decade to 1 in 3,062 . In the previous series at our same institution between 1972 and 1982, the incidence was 1 in 3,869. ${ }^{1}$ Between 1983 and 1992, the incidence was 1 in 6,331. ${ }^{2}$ This is comparable to rupture rates of other developed countries after year 2000, such as Saudi Arabia, Taiwan and France. ${ }^{1-8}$

Previous uterine scars are known risk factors for uterine rupture. ${ }^{9}$ A history of previous caesarean sections is the most common reason for a scarred uterus. There is a global trend moving towards caesarean sections. Caesarean section incidence has been increasing, rising from $12 \%$ of live births in 2000 to $21 \%$ in 2015 . In North America, Western Europe and Latin America, caesarean section rates rose by around $2 \%$ a year between 2000 and 2015 to $32 \%, 27 \%$ and $44 \%$, respectively. In more than 15 countries, caesarean section rates have surpassed $40 \% .{ }^{10}$ In Singapore, caesarean section rates have been steadily increasing from $17.8 \%$ in 1999 to $34 \%$ in 2009 , and $37.4 \%$ in $2014 .{ }^{11,12}$ The main indication for caesarean section in 1999 was cephalopelvic disproportion but a decade later, history of 1 previous caesarean section became the most common indication. ${ }^{11}$ While the procedure can reduce mortality and morbidity in suitable cases, indiscrete use can inflict unnecessary complications and risk for mothers, especially in future births.

Vaginal birth after caesarean section (VBAC) remains the most common cause for a scarred uterus rupture in our study. The highest rate of uterine rupture in these patients occur intrapartum. Ultrasound of scar thickness has not shown to reliably predict rupture risk. Our institution does not offer trial of labour after 2 previous sections. Mothers who are keen for trial of labour after more than 1 previous caesarean may seek a second opinion at an alternative institution. Compared to spontaneous VBAC labour, induced and/or augmented labour had a 2- to 3-fold increased risk of uterine rupture and around 1.5-fold increased risk of caesarean delivery. ${ }^{13}$ Prostaglandins used for cervical ripening and induction of labour have been associated with increased risk of rupture when used in patients with previous cesarean sections. ${ }^{14}$ A study by Lydon-Rochelle ${ }^{14}$ found that the incidence of rupture when oxytocin was used during a VBAC was 7.7 per 1,000 . In our case series, prostaglandin was used in 3 out of 20 cases of VBAC, while 2 cases had oxytocin use. This is much lower than that reported in other studies in the US ${ }^{15}$ and China, ${ }^{16}$ where the rates of labour augmentation with oxytocin in
VBAC cases quoted were $27.7 \%$ and $25.5 \%$, respectively. Cautious use of these agents is essential to minimise risk of uterine rupture.

There are no guidelines to recommend duration for trial of labour after VBAC. Up to 1 in 5 cases had prolonged active labour duration of more than 12 hours in our case series. Timely review of VBAC patients to assess feasibility of success of labour by a senior obstetrician is recommended.

One of the most important risk factors in uterine rupture is a history of laparoscopic myomectomy. ${ }^{17}$ The second most common cause of scarred uteri in our case series is a previous history of laparoscopic myomectomy. All cases of rupture had laparoscopic approach for their previous myomectomy. There were no cases of rupture from a history of open myomectomy. The rupture rates after laparoscopic myomectomy are variable, as high as $10 \%{ }^{18-22}$ The technique of repair with laparoscopic suturing following myomectomy could be a contributing factor to the integrity of the scar subjected to a trial of labour.

Bernadi ${ }^{21}$ suggested a few factors that increase the incidence of uterine rupture after myomectomy. This included short duration between myomectomy and conception (less than 12 months), opening of endometrial cavity, and patients with large myomas more than $4 \mathrm{~cm}$. The extensive use of electro-surgery leads to poor vascularisation and necrosis of the myometrium. . $^{18,21,23}$ This decreases scar strength and predisposes to uterine rupture. Appropriate use of electro-surgery and multilayered closure of the myometrium are essential for the prevention of uterine rupture after a laparoscopic myomectomy. ${ }^{24}$ Avoidance of entry into the endometrial cavity and prevention of haematoma formation are also extra precautions. The use of Morphological Uterus Sonographic Assessment (MUSA) classification to better classify myomas and predict the risk of uterine rupture in subsequent pregnancies is a plausible idea. ${ }^{25}$ Further studies need to be performed to validate the effectiveness of the MUSA classification.

In our study, the majority of ruptures in women with a previous laparoscopic myomectomy occurred in the third trimester. A recent meta-analysis supports that up to $80 \%$ of uterine ruptures after laparoscopy myomectomy occur between 28 and 36 weeks of gestation. ${ }^{26}$ However, some case series have shown early preterm uterine ruptures, as early as 10 weeks of gestation after laparoscopic myomectomy. Makino ${ }^{4}$ suggested that uterine rupture occurred earliest in patients after adenomyomectomy, followed by myomectomies in those with caesarean section. Obstetricians should exercise extra caution antenatally with this subgroup, even in the first trimester. 
Of note, patients with previous laparoscopic myomectomy presented almost exclusively antenatally. All our patients in this subgroup ruptured antenatally in our case series, with 1 case complicated by end organ damage from hypovolaemic shock. Consequently, fetal loss rate appears to be higher in this subgroup of women compared to women with scarred uteri from previous caesarean sections. Claeys ${ }^{27}$ examined 29 cases, with 1 case of rupture intrapartum, and 28 cases of rupture before the onset of labour. These women may also have atypical presentations of pain mimicking appendicitis and abruption, which warranted a high index of suspicion. Careful counselling of young women of reproductive age following a laparoscopic myomectomy regarding pain in the third trimester appears to be useful.

Pregnancy after laparoscopic myomectomies, however, can be uncomplicated. A case series by Kumakiri ${ }^{28}$ of 111 patients who conceived following laparoscopic myomectomy had successful term deliveries with no cases of ruptures. Of these patients, 52 had caesarean sections and 59 underwent successful vaginal deliveries.

Uterine rupture may also happen to women who have no previous uterine scars. While rare, we captured 12 such cases in our series. One in 4 of our patients who experienced uterine rupture had unscarred uteri. Of these 12 patients, 6 were primiparous. Of these 6 primiparous patients, 3 patients ruptured antenatally in their second trimester at the uterine fundus, and the histology of one of these cases returned as placenta accreta. This latter condition is unusual. The retrospective nature of this study limits our ability to obtain more details on these cases. Previous literature review by Lydon-Rochelle ${ }^{14}$ found an incidence of 1 in 8,000 to 1 in 1,500. Zwart et al. ${ }^{8}$ reported 25 cases of rupture in unscarred uteri, with an overall incidence of 0.7 in 10,000. Multiple factors are associated with rupture in the unscarred uteri. These include: a history of instrumental abortion or postpartum curettage, history of hysteroscopy, uterine anomalies, multiple gestations, macrosomia, oxytocin stimulation, prostaglandin use, undiagnosed malpresentation, forced manipulation of the birth canal such as cervical dilatation and breech extraction, and obstetric trauma. ${ }^{8,9,29}$

An interesting finding was that a high proportion of ruptures in the unscarred uteri group in our series occurred in the fundus. The fundus is the most common rupture site in unscarred uteri in the literature. ${ }^{17}$ It has been postulated that a history of previous termination of pregnancies and other uterine procedures could be withheld from the clinician, which could be a contributory factor to this phenomenon.

There were no maternal deaths in our case series, and there was an overall rate of $10.4 \%$ for hysterectomies done after uterine rupture. Varying rates of hysterectomy from $6.7 \%$ up to $71.5 \%$ have been reported. $1,3,5,8,30$ Hysterectomy, whether total or subtotal, is a common surgical procedure in cases of uterine rupture. Haemoperitoneum is a common finding, and early recognition is crucial to avert severe hypotension and possible end organ damage.

The incidence of fetal loss was $25.0 \%$ in our study. This could be related to the high incidence of antenatal rupture in our review (41.7\%). Other studies have quoted fetal loss rates varying from $12.2-84.1 \% .^{1,3,5,30}$ Although our study did not show significant differences in maternal and neonatal outcomes between the scarred and unscarred groups, severe maternal and neonatal morbidity and mortality were more often observed among women with an unscarred uterine rupture, as compared to uterine scar rupture in other studies. Zwart et al. ${ }^{8}$ reported significantly higher maternal intensive care unit admissions, hysterectomy rates, major blood loss and peripartum fetal death in the unscarred uteri group. As discussed, it appears that ruptures in cases with previous laparoscopic myomectomy have worse fetal outcomes than those with a history of caesarean section. Makino $^{4}$ reviewed uterine rupture in 112 women with scarred uteri, and showed that neonatal death is most prevalent in those with previous adenomyomectomy, followed by laparoscopic myomectomy, and is the least in those with caesarean section. This is likely related to the timing of ruptures. Mothers with previous laparoscopic myomectomy tend to present antenatally, and earlier in the course of their pregnancy, when fetuses are premature. They may also present with signs mimicking acute abdomen or appendicitis, making diagnosis more difficult, and thus management can potentially be delayed. In contrast, those with previous caesarean section tend to present intrapartum, where they are on continuous fetal monitoring. Signs of rupture are likely to be observed earlier, leading to improved fetal outcomes.

The retrospective nature of this review would mean that the data was dependent on the accuracy of the diagnosis that was recorded. This possibly explains why there were no recorded uterine rupture cases in the first trimester, as these cases were likely classified as ruptured ectopic pregnancies. As the largest obstetric public institution in Singapore, our data is likely to reflect most acute cases sent by ambulance. The numerator data could be overrepresented as evidenced by the fact that all the cases of uterine rupture after a laparoscopic myomectomy were performed at other centres. In addition, the ratio of deliveries in the public versus private sectors has changed over the past decade. This will affect the denominator 
value as well. Therefore, our incidence of rupture could be subjected to such bias.

\section{CONCLUSION}

Compared to the previous series at the same institution, there is a notable change in the trend of uterine rupture cases in Singapore given the increasing use of laparoscopic myomectomy and elective caesarean sections. While rupture from these cases are few, their presentation in the antenatal period calls for diligent monitoring with informed patient involvement in their pregnancy care. Meticulous review of previous surgical documentation and photos, detailed counselling, close follow-up and early identification of these at-risk patients is crucial to optimise outcomes for uterine rupture cases. A high degree of vigilance should remain when patients with a scarred uterus undergo a trial of vaginal birth, and induction of labour for this group of patients should be done after careful counselling. Unscarred uteri can also rupture. Discreet enquires about previous uterine instrumentation at the booking visit could help identify some women at risk.

\section{REFERENCES}

1. Chew SY. Uterine rupture in labour. A 10-year review. Singapore Med J 1984;25:24-9.

2. Chen LH, Tan KH, Yeo GS. A ten-year review of uterine rupture in modern obstetric practice. Ann Acad Med Singap 1995; 24:830-5.

3. You SH, Chang YL, Yen CF. Rupture of the scarred and unscarred gravid uterus: Outcomes and risk factors analysis. Taiwan J Obstet Gynecol 2018;57:248-54.

4. Makino S, Takeda S, Kondoh E, et al. National survey of uterine rupture in Japan: Annual report of Perinatology Committee, Japan Society of Obstetrics and Gynecology, 2018. J Obstet Gynaecol Res 2019;45:763-5.

5. Turgut A, Ozler A, Siddik Evsen M, et al. Uterine rupture revisited: Predisposing factors, clinical features, management and outcomes from a tertiary care center in Turkey. Pak J Med Sci 2013;29:753-7.

6. Sayed Ahmed WA, Habash YH, Hamdy MA, et al. Rupture of the pregnancy uterus - a 20-year review. J Matern Fetal Neonatal Med 2016;30:1488-93

7. Markou GA, Muray JM, Poncelet C. Risk factors and symptoms associated with maternal and neonatal complications in women with uterine rupture. A 16 years multicentric experience. Eur J Obstet Gynecol Reprod Biol 2017;217:126-30.

8. Zwart JJ, Richters JM, Ory F, et al. Uterine rupture in The Netherlands: a nationwide population-based cohort study. BJOG 2009;116:1069-78.

9. Mazzone ME, Woolever J. Uterine rupture in a patient with an unscarred uterus: a case study. WMJ 2006;105:64-6.

10. Boerma T, Ronsmans C, Melesse DY, et al. Global epidemiology of use of and disparities in caesarean sections. Lancet 2018;392:1341-8.
11. Wang CCP, Tan WC, Kanagalingam D, et al. Why we do caesars: a comparison of the trends in caesarean section delivery over a decade. Ann Acad Med Singap 2013;42:408-12.

12. Chi C, Pang D, Aris IM, et al. Trends and predictors of cesarean birth in Singapore, 2005-2014: A population-based cohort study. Birth 2018;45:399-408.

13. RCOG Green Top Guidelines No.45, Birth after Previous Caesarean Birth, 1 October 2015.

14. Lydon-Rochelle M, Holt VL, Easterling TR, et al. Risk of uterine rupture during labor among women with a prior cesarean delivery. N Engl J Med 2001;345:3-8

15. Abraham C, Adeyekun M, Demissie S, Patterns of Oxytocin Use in Those Undergoing Trial of Labor After Cesarean Delivery. Gynecol Obstet (Sunnyvale) 2017;129:S147.

16. Wu SW, Dian H, Zhang WY. Labor Onset, Oxytocin Use, and Epidural Anesthesia for Vaginal Birth after Cesarean Section and Associated Effects on Maternal and Neonatal Outcomes in a Tertiary Hospital in China: A Retrospective Study. Chin Med J (Engl) 2018;131:933-8.

17. Okada Y, Hasegawa J, Mimura T, et al. Uterine rupture at 10 weeks of gestation after laparoscopic myomectomy. J Med Ultrason (2011) 2016;43:133-6.

18. Dubuisson JB, Fauconnier A, Deffarges JV, et al. Pregnancy outcome and deliveries following laparoscopic myomectomy. Hum Reprod 2000; $15: 869-73$

19. Malzoni M, Sizzi O, Rossetti A, et al. Laparoscopic myomectomy: a report of 982 procedures. Surg Technol Int 2006;15:123-9.

20. Sizzi O, Rossetti A, Malzoni M, et al. Italian multicenter study on complications of laparoscopic myomectomy. J Minim Invasive Gynecol 2007;14:453-62.

21. Bernardi TS, Radosa MP, Weisheit A, et al. Laparoscopic myomectomy: a 6-year follow-up single-center cohort analysis of fertility and bstetric outcome measures. Arch Gynecol Obstet 2014;290:87-91.

22. Koo YJ, Lee JK, Lee YK, et al. Pregnancy Outcomes and Risk Factors for Uterine Rupture After Laparoscopic Myomectomy: A Single-Center Experience and Literature Review. J Minim Invasive Gynecol 2015;22:1022-8.

23. Yazawa H, Takiguchi K, Ito F. Uterine rupture at 33 rd week of gestation after laparoscopic myomectomy with signs of fetal distress. A case report and review of literature. Taiwan J Obstet Gynecol 2018;57:304-10.

24. Parker WH, Einarsson J, Istre $\mathrm{O}$, et al. Risk factors for uterine rupture after laparoscopic myomectomy. J Minim Invasive Gynecol 2010;17:551-4.

25. Vimercati A, Del Vecchio V, Chincoli A, et al. Uterine Rupture after Laparoscopic Myomectomy in Two Cases: Real Complication or Malpractice? Case Rep Obstet Gynecol 2017;2017:1404815.

26. Kim HS, Oh SY, Choi SJ, et al. Uterine rupture in pregnancies following myomectomy: A multicenter case series. Obstet Gynecol Sci 2016;59:454-62

27. Claeys J, Hellendoorn I, Hamerlynck T, et al. The risk of uterine rupture after myomectomy: A systematic review of the literature and meta-analysis. Gynecological Surgery 2014;11:197-206.

28. Kumakiri J, Takeuchi H, Itoh S, et al. Prospective evaluation for the feasibility and safety of vaginal birth after laparoscopic myomectomy. J Minim Invasive Gynecol 2008;15:420-4

29. Pearlman MD, Tintinalli JE, Lorenz RP. Blunt trauma during pregnancy. N Engl J Med 1990;323:1609-13.

30. Ahmed DM, Mengistu TS, Endalamaw AG. Incidence and factors associated with outcomes of uterine rupture among women delivered at Felegehiwot referral hospital, Bahir Dar, Ethiopia: cross sectional study. BMC Pregnancy Childbirth 2018;18:447. 